maximum posterior wall velocity and excursion when compared with the values of normal resting subjects. The remaining five patients had no clinical evidence of left ventricular failure; however, our measurements showed depression of posterior wall velocity and excursion, suggesting impairment of ventricular function within the first 36-hour period.

Pulmonary artery diastolic pressure has been shown to be a good indicator of left ventricular end-diastolic pressure, particularly in the acute situation (Kaltman et al., 1966; Abbott, 1970; Jenkins et al., 1970). In the two patients we studied the pulmonary artery diastolic pressure was raised when maximum posterior wall velocity and excursion were depressed and reverted to normal levels as the maximum wall velocity and excursion increased. This relationship adds further substance to the usefulness of ultrasound in reflecting changes in left ventricular function after acute anterior myocardial infarction.

The use of this bedside technique could prove a considerable aid to the clinician in the assessment and treatment of patients in cardiogenic shock or severe cardiac failure after infarction. The beneficial and deleterious effects of any therapy on myocardial function could be monitored with the minimum of disturbance to the patient.
We are grateful to the British Heart Foundation for a grant to one of us (C.F.P.W.) for the purchase of this equipment.

\section{References}

Abbott, J. A. (1970). Cardiovascular Research: VI World Congress of Cardiology, Abstracts, p. 58

Bowyer, A. F., Jutzy, R. V., Coggin, V., Crawford, R. B., and Johns, V. J., jun. (1968). American fournal of Cardiology, 21, 92 (abstract). Fluck, D. C., et al., (1967). British Heart foumal, 29, 748

Hodges, M., Marx, H. J., Schreiner, B., and Yu, P. N. (1971). American fourmal of Cardiology, 26, 638 (abstract).

Jenkins, B. S., Bradley, R. D., and Branthwaite, M. A. (1970). Circulation, 42, 75 .

Kaltman, A. J., Herbert, W. H., Conroy, R. J., and Kossman, C. E. (1966). Circulation, 34, 377 .

Krauntz, R. F., and Kennedy, J. W. (1970). American Heart foumal, 79, 36.

Krauntz, R. F., and Ryan, T. J. (1971). American fournal of Cardiology, 27,464

Murphy, G. W., Glick, G., Schreiner, B. F., and Yu, P. N. (1963). American fournal of Cardiology, 11, 587.

Russel, R. O., jun., Hunt, D., and Rackley, C. E. (1971). American Fournal of Cardiology, 26, 658 (abstract).

Scheidt, S., Ascheim, R., and Killup, T. (1971). American fournal of Cardiology, 26. 556.

Smithen, C. S., Wharton, C. F. P., and Sowton, E. (1971). American fournal of Cardiology. Submitted for publication.

Wharton, C. F. P., Smithen, C. S., and Sowton, E. (1971). Medical Research Society Meeting, May 1971.

\title{
Left Ventricular Wall Movement in Heart Failure
}

\author{
PETER CARSON, LAWRENCE KANTER
}

\section{British Medical fournal, 1971, 4, 77-79}

\section{Summary}

Of 34 patients admitted to hospital with left ventricular failure seven died before echocardiograms could be repeated after treatment and in three no echocardiograms could be obtained owing to chronic obstructive lung disease. In the remaining 24 patients echocardiograms were taken soon after admission and compared with echocardiograms taken later, after clinical improvement. The results show that in most patients both anterior and posterior motion of the posterior left ventricular wall increased. The rate of backward diastolic motion was appreciably less before and after treatment of heart failure compared with that in a small group of normal younger healthy men. This technique is a quick and apparently reliable way to assess ventricular function. The rate of diastolic motion is probably a reflection of left ventricular wall compliance.

\section{Introduction}

Ultrasound is, by generally accepted definition, sound with a wave frequency exceeding $18 \mathrm{kHz}$. The ultrasonic reflection technique was first used for cardiological investigations by Edler and Hertz (1954). Since that time ultrasound, or "echocardiographic" techniques have been used in several fields of cardiology. The anterior cusp of the mitral valve has been

\footnotetext{
Cardiac Catheterization Laboratory, Cleveland Metropolitan General Hospital, Ohio, U.S.A.

PETER CARSON, M.R.C.P., F.A.C.C., Director (At Present Consultant Cardiologist, North Staffordshire Hospital Group, Stoke-on-Trent)

Albert Einstein Medical Centre, Bronx, New York, U.S.A. LAWRENCE KANTER, M.D., Medical Intern
}

extensively studied, and the echocardiogram has proved to be of clinical value in the assessment of the presence and severity of mitral stenosis (Edler, 1967; Gustafson, 1967; Segall et al., 1967). Pericardial effusions can be recognized by this technique (Feigenbaum et al., 1965), and it seems likely that associated tamponade can be detected by the diminished motion of the posterior heart wall (Feigenbaum et al., 1967). The thickness of the posterior left ventricular wall has also been assessed by this technique (Feigenbaum et al., 1968; Sjögren et al., 1970).

In left ventricular failure it is well known that the left ventricular cavity is dilated and that angiographic assessments indicate that the rate of motion of the left ventricular wall is diminished. The echocardiographic technique would seem to lend itself to quantitating the amplitude of posterior wall motion and also the rate of forward and backward movement. This belief stimulated the present work.

\section{Subjects and Methods}

Two groups of subjects were studied. The first consisted of five healthy men aged 22-28 with no overt evidence of heart disease. In the second group were 34 patients (19 men and 15 women) who were admitted with left ventricular failure. All patients were dyspnoeic at rest-that is, in New York Heart Association classification group IV. The diagnosis of left ventricular failure was based on clinical assessment, and all patients had $x$-ray films which showed cardiomegaly and obvious changes of pulmonary venous hypertension.

In three patients with chronic obstructive lung disease as well as left ventricular failure no satisfactory echocardiograms could be obtained; sound does not penetrate lung tissue well, and satisfactory echocardiograms are consequently difficult or impossible to obtain in patients with overexpanded lungs due to emphysema. In seven other patients death occurred before clinical improvement and repeat echocardiograms could be 
performed. In the remaining 24 patients echocardiograms were obtained soon after admission and again after clinical and radiological improvement had occurred. The intervals between the first and second echocardiographic studies ranged from 4 to 29 days, with a mean of 11 days. The ages of the patients and the aetiology of their heart failure are shown in Table II.

The echocardiograms were taken with a Hewlett-Packard diagnostic sounder, which emits 1,000 pulses per second at a frequency of $2.5 \mathrm{MHz}$. All the echocardiograms were taken with the time-motion scan. The technique was greatly facilitated by the incorporated memory scope, since this allowed repeated

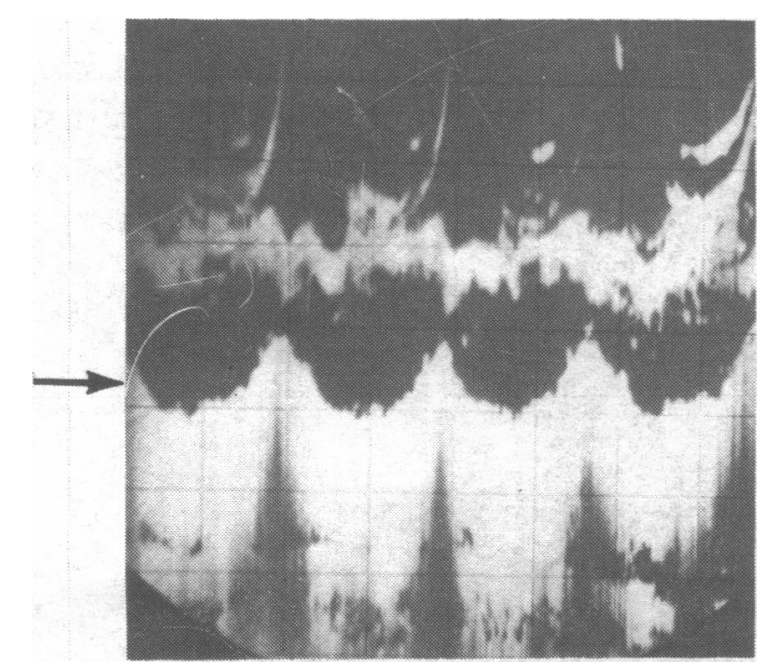

The ultrasound is directed to record the movements of the posterior wall of the left ventricle indifigure) is the anterior cusp of the mitral valve.

TABLE I-Results in the Five Normal Subjects

\begin{tabular}{|c|c|c|c|c|}
\hline \multirow{2}{*}{$\begin{array}{c}\text { Subject } \\
\text { No. }\end{array}$} & \multirow{2}{*}{$\underset{(\mathbf{c m})}{\text { Diameter }}$} & \multicolumn{3}{|c|}{ Posterior Wall Motion } \\
\hline & & $\underset{(\mathrm{cm})}{\text { Amplitude }}$ & $\begin{array}{c}\text { Rate of Rise } \\
(\mathrm{cm} / \mathrm{sec})\end{array}$ & $\begin{array}{l}\text { Rate of Fall } \\
(\mathrm{cm} / \mathrm{sec})\end{array}$ \\
\hline $\begin{array}{l}\ldots \\
\because \\
\because \\
\cdots\end{array}$ & $\begin{array}{l}4 \cdot 6 \\
4 \cdot 0 \\
4 \cdot 1 \\
4 \cdot 0 \\
4 \cdot 8\end{array}$ & $\begin{array}{l}1.4 \\
1.7 \\
1.4 \\
1.5 \\
1.6\end{array}$ & $\begin{array}{l}5 \cdot 9 \\
6 \cdot 8 \\
5 \cdot 6 \\
5 \cdot 1 \\
6.1\end{array}$ & $\begin{array}{r}11 \cdot 1 \\
13.2 \\
8.9 \\
6.6 \\
13.7\end{array}$ \\
\hline Mean & $4 \cdot 3$ & 1.5 & 5.9 & $10 \cdot 7$ \\
\hline
\end{tabular}
cated by an arrow. Anterior to this (higher in the traces to be examined before the best were selected for photography.

The following measurements were made:

(1) Anteroposterior diameter measuring from the posterior border of the anterior heart wall to the front of the posterior left ventricular wall (see Fig.). The echocardiograms for these measurements were taken from the left sternal border in the intercostal space which showed the maximum diameter. The results are given in centimetres.

(2) The maximum amplitude of posterior left ventricular wall movement. These echocardiograms were taken in a position which showed the greatest posterior wall movement, and this was not necessarily in the same position as that which reflected the maximlim anteroposterior diameter. The results are expressed in centimetres.

(3) The rate of rise of the posterior wall movement-that is, the rate of the anterior excursion. The results are expressed in $\mathrm{cm} / \mathrm{sec}$.

(4) The rate of fall-that is, the rate of posterior motion of the left ventricular posterior wall. The results are expressed in $\mathrm{cm} /$ sec.

\section{Results}

The results in the normal subjects are shown in Table I. The results in the patients with left ventricular failure are shown in Table II. In Table III the means and the ranges of the four measurements are shown in the normal subjects, and also in the patients with left ventricular failure before and after clinical improvement. Student's $t$ test was used for the statistical analysis; this showed no difference between male and female patients, and the heart failure group is therefore taken together for comparison with the normal men.

Anteroposterior Diameter.-This was increased, as would be expected, in the patients compared with the young normal men. In 23 patients clear anteroposterior diameters could be measured -21 showed a decrease with clinical improvement, one showed

TABLE III-Means (and Ranges) of Four Measurement in Normal Subjects and in Patients with Left Ventricular Failure before and after Clinical Improvement

\begin{tabular}{|c|c|c|c|}
\hline & \multirow{2}{*}{ Normal Subjects } & \multicolumn{2}{|c|}{ Patients with Left Ventricular Failure } \\
\hline & & $\begin{array}{l}\text { Initial } \\
\text { Values }\end{array}$ & $\begin{array}{l}\text { After Clinical } \\
\text { Improvement }\end{array}$ \\
\hline $\begin{array}{l}\text { A-P diameter }(\mathrm{cm}) \\
\text { Amplitude }(\mathrm{cm}) \\
\text { Rate of rise }(\mathrm{cm} / \mathrm{sec}) \\
\text { Rate of fall }(\mathrm{cm} / \mathrm{sec})\end{array}$ & $\begin{array}{c}4 \cdot 3(4 \cdot 0-4 \cdot 8) \\
1 \cdot 5(1 \cdot 4-1 \cdot 7) \\
5 \cdot 9(5 \cdot 1-6 \cdot 8) \\
10 \cdot 7(6 \cdot 6-13 \cdot 7)\end{array}$ & $\begin{array}{l}6 \cdot 4(3 \cdot 7-8 \cdot 4) \\
0 \cdot 7(0 \cdot 5-1 \cdot 4) \\
3 \cdot 3(1 \cdot 3-5 \cdot 0) \\
3 \cdot 1(1 \cdot 5-5 \cdot 0)\end{array}$ & $\begin{array}{l}5 \cdot 5(3 \cdot 0-8 \cdot 0) \\
1 \cdot 0(0 \cdot 5-1 \cdot 7) \\
4 \cdot 8(1 \cdot 8-9 \cdot 6) \\
4 \cdot 6(2 \cdot 1-10 \cdot 0)\end{array}$ \\
\hline
\end{tabular}

TABLE II-Sex, Age, Aetiology, and Results in the 24 Patients. Results are Shown before and after Clinical Improvement in the Heart Failure

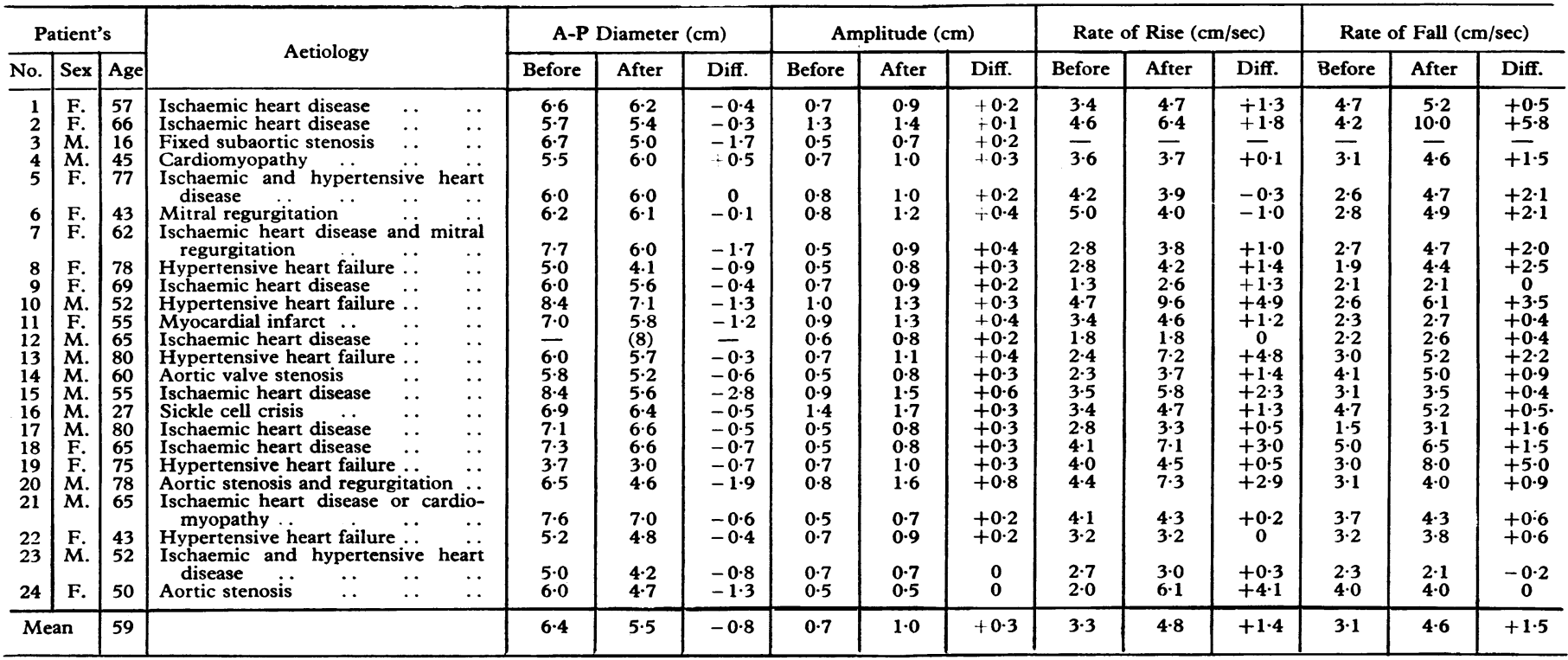


no change, and one showed an increase. The mean decrease was $0.8 \mathrm{~cm}$, and the range of change was from +0.5 to $-2.8 \mathrm{~cm}$. The increased anteroposterior diameter is significantly different from that of the normal group, both before $(P<0.001)$ and after $(P<0.01)$ treatment of the heart failure. The decrease in the diameter with clinical improvement after treatment is significant $(\mathrm{P}<0.001)$.

Amplitude of Posterior Wall Movement.-The amplitude was greater in the normal men than in the patients with heart failure. In 22 out of the 24 patients the amplitude increased and in two there was no change. The difference between the normal group and the patients before and after treatment of heart failure was significant $(P<0.001$ and $<0.002$ respectively). The increase in amplitude following the treatment of heart failure was also significant $(P<0.001)$.

Rate of Rise.-The anterior motion was greatest in the normal men. After improvement of heart failure 19 patients showed an increase in the rate of rise, two no change, and two a decrease. The mean increase in the rate of rise was $1.4 \mathrm{~cm} / \mathrm{sec}$, with a range of -1 to $+4.9 \mathrm{~cm} / \mathrm{sec}$. The difference between the normal group and the patients before treatment of heart failure was significant $(P<0.001)$. After treatment the difference between the normal and patient groups was no longer significant at the $5 \%$ level. The increase in the amplitude in the patient group after treatment was significant $(P<0.001)$.

Rate of Fall.-The rate of posterior motion was greatest in the normal men. Twenty patients in the heart failure group showed an increase in their rate of fall after clinical improvement, two no change, and one a slight decrease. The mean change was $1.5 \mathrm{~cm} / \mathrm{sec}$, with a range of -0.2 to $+5.8 \mathrm{~cm} / \mathrm{sec}$. The difference between the normal and patient groups was significant both before and after clinical improvement in the patients $(P<0.001)$. The increase in the rate of fall after clinical improvement in the patient group was significant $(P<0.001)$.

\section{Discussion}

The results are in agreement with the generally accepted views about heart failure and its response to treatment. As would be expected the four measurements showed "improvement" in most patients after clinical improvement.

The anteroposterior diameter was largest in the patients in heart failure and smallest in the small group of normal men. The anteroposterior diameter assessed by this technique is obviously not necessarily purely a reflection of left ventricular cavity size. In some patients there was right ventricular failure secondary to left ventricular at the time of the initial study, and the anteroposterior diameter measured echocardiographically may have been further enlarged if the right ventricle was dilated and the septum rotated toward the left. It would be interesting to perform these measurements on a group of patients with cor pulmonale without overt left ventricular disease.

The amplitude of left ventricular posterior wall motion showed the expected changes, being greatest in the normal men and least in the patients in heart failure. The increased amplitude with recovery from heart failure was to be anticipated from the improvement in heart function.
The rate of rise-that is, systolic anterior motion-showed an increase in most patients and can reasonably be considered to indicate an improvement in "myocardial contractility." After improvement in heart failure the anterior motion increased much more than did the diastolic posterior motion; indeed the difference between the rates of anterior motion in the patients after treatment of heart failure and in the control group was not significant at the $5 \%$ level.

The most interesting of our results is the change in the rate of fall-that is, the rate of posterior motion. This is greatest in the normal men and is impressively less in the patients with heart failure. After clinical improvement the rate of fall increases but it is still much less than in the normal subjects. Since we do not have left atrial pressures or left ventricular volume measurements at the time these studies were made, it is impossible to equate the rate of fall with changes in left ventricular compliance. Nevertheless, it is reasonable to suppose that the left atrial pressure was increased in all the patients at the time of the initial echocardiographic studies. If the primary factor in determining the rate of backward motion was the filling pressure of the ventricle it would be expected that the rate of fall would be increased in heart failure. The reverse is the case, and it would seem therefore that the rate of backward motion is a reflection of the impaired compliance of the left ventricle. This measurement may prove valuable in the assessment of patients with left ventricular disease before the clinical development of heart failure. Similarly it may prove helpful in the assessment of prognosis after cardiac surgery.

In this work we used as the control group a small number of subjects who were younger than the patient group. The choice of the young was intentional, since we do not know at present whether the echocardiographic measurements which were taken are altered in elderly subjects owing to coronary artery disease which is not clinically evident.

We are grateful to Mr. D. C. E. Manley, senior lecturer in statistics, North Staffordshire Biomedical Engineering Unit, North Staffordshire Polytechnic, Stoke-on-Trent, who kindly performed the statistical analysis for us. We thank Miss Gladys Heckman, Miss Hanna Janouskovec, and Miss Joanne McAllister for much technical help.

This work was supported by grants from Case Western Reserve University (Nos. 642-9690 and 642-9784) and from the Health Fund of Greater Cleveland (642-5859).

\section{References}

Edler, I. (1967). American fournal of Cardiology, 19, 18.

Edler, I., and Hertz, C. H. (1954). Kungliga Fysiografiska Sällskapets Lund i Fördhandlingar, 24, 1.

Feigenbaum, H., Waldhausen, J. A., and Hyde, L. P. (1965). fournal of the American Medical Association, 191, 711.

Feigenbaum, H., Zaky, A., and Waldhausen, J. A. (1967). American fournal of Cardiology, 19, 84

Feigenbaum, H., Popp, R. L., Chip, J. N., and Haine, C. L. (1968). Archives of Internal Medicine, 12i, 391 .

Gustafson, A. (1967). American fournal of Cardiology, 19, 32.

Segall, B. L., Likoff, W., and Kingsley, B. (1967). American fournal of Cardiology, 19, 50 .

Sjögren, A. L., Hytönen, I., and Frick, M. H. (1970). Chest, 57, 37. 